Studia UBB 政igitalia, Volume 62 (LXII) 2017, December, Issue 2, 63-72

Published Online: 2017-12-30

DOI:10.24193/subbdigitalia.2017.2.04

\title{
Past and present of the field of informatics at "Babeș-Bolyai" University and other institutions in Cluj-Napoca ${ }^{1}$
}

\author{
Grigor Moldovan \\ Babeș-Bolyai University Cluj-Napoca
}

\begin{abstract}
This article is centered on the story of the pioneering endeavors in the field of informatics in Romania and more specifically in Cluj-Napoca. Stemming from personal experience and reverence towards the very first professors and specialists that opened up this vast and formidable domain, this article which reads as a history of Romanian informatics, has the added benefit of filling in a noticeable gap in texts that take into account this interesting subject. Spanning from the 50s and all the way up to the 90s and tracing the opening, and transformations, and eventual closure of research centers, laboratories, and various institutional collaborations, this article brigs a better understanding of the efforts and challenges that are always seem to be intertwined with progress, but which were eventually overcome through the persistence of brilliant scholars, and sometimes even the occasional favorable policy. Special attention is given to the entity of the Calculus Centre at Babeș-Bolyai University, founded in 1975, as the author himself was its director for 17 years until it was dismantled in 1992. This too however did not mark and end, but rather a new beginning, a different model of institution that was meant to tackle the ever-changing issues informatics face today.
\end{abstract}

Keywords: Informatics; history of informatics; institutional transformation

${ }^{1}$ Translation by Voica Puşcaşiu 
The words "informatics" and "computer" are today part of people's vocabulary, especially for the younger generation, along the most-used words. Further on, we are so accustomed to using a phone, eventually even a mobile device which allows us to communicate everywhere in the world and with anyone we desire almost instantaneously, we then flip through the television channels from the comfort of our armchairs using a remote control and many, many others. Today's world has become dependent on computers, a fact which was unimaginable years ago. The Internet phenomenon has a fantastic social, economic, and perhaps even cultural impact in the world we live in that is not to be understated. Let us thing about how much the communication distance between people has been reduced by the internet, as compared to the time it took for a letter to travel to a destination carrying a message. What wonderful transformations flow from this from a human perspective, which we might not even register at this moment! Everything happens naturally, as if these things were here since the dawn of time.

All the technical conquests of today are influencing people's lives, it is sufficient to take into considerations the afore-mentioned ones to be utterly convinced of this fact. In the domain of human relations, even on a sentimental level there have been important changes. Everything happens in a much too short time span and with a much larger reaction time. Let us remark that for child today, all these things seem usual and normal.

What is the price of this high-impact modernization, which reduces distances, compresses time, speeds up the reaction time, the speed of dissemination, adds new pleasures, modifies feelings and human psychologies? There surely is a price, for example stress, but perhaps even others in the medical field and beyond. Some consequences will be noticed shortly, while others might not, in any case the unwanted ones we will be able to prevent, attenuate, and eventually even eliminate.

We mentioned some of these truly revolutionary things that have taken place in the last few years in order to convince every beneficiary of these technical and scientific successes that every once in a while we should at least mention some of those who contributed with their minds and knowledge to their existence, namely their pioneers. I believe that these pioneers are many. The distinction between them lies in the fact that some knew and were able to gain a certain popularity, while others were not interested in this aspect, perhaps being overwhelmed by work, or they were simply not allowed to present their outcomes, perhaps even due to others' envy. There is nothing normal in any of this. The essence lies in the fact that there are pioneers in every domain we have mentioned. There are thus pioneers in the field of informatics on the local scene, on the national one, and evidently on an international level.

In our country, it is quite remarkable the high receptivity with which the majority of ideas and conquests of advance sciences and technology have been adopted. In the domain of informatics and computers, the interest in this sense was notable in the main 
university centers: Cluj-Napoca, Timișoara, and Iași. In the universities, polytechnic institutes, and research institutes there have been enthusiastic specialists, which have dedicated themselves to pioneering activities in the field of informatics.

I will take into account in a few words the activities of the university centre of Cluj, where there has been research and questions about developing large-scale programs in computing and informatics.

I have to mention that the first of these have taken place in the Calculus Institute of the Romanian Academy, under the directorship of the academician Tiberiu Popoviciu. The mentioned nomenclature of the institute dates form 1951, while initially, in 1948 it was named the Mathematics Institute of the Romanian Academy, Branch of Cluj-Napoca. This institute was drastically reorganized in 1974. It was here where many of the professors of the Faculty of Mathematics in Cluj were active. Obviously, the institute had its own personal on research organized into sections and laboratories. One of them was the Calculus Laboratory where mathematicians such as Liviu Negrescu, Emil Munteanu, and Teodor Rus worked together with engineers like Manfred Rosmann, Gheorghe Farkas, ad Ionalda Juhasz among other specialists. In 1959, under the leaderships of Manfred Rosmann the relay and other automatic devices calculus machine has been built in laboratory conditions. It has been named MARICA (Automatic Relay Machine of the Calculus Institute of the Academia) and it constituted a fine technical and mathematical exercise into how an automatic calculator should look like, despite the fact that this arithmetic calculus machine has never worked. This achievement has been announced in an Italian journal and a real school has taken shape in this field. This was followed in 1959-63 by the building, in the same institute, of the computer DACICC-1 (Automatic Dispositive of Calculus of the Calculus Institute of Cluj), which has as construction elements electronic tubes and transistors and effectively worked, being able to roll programs in machine language that were introduces in its internal memory through perforated bands or through the keyboard of a console. The next computer created in this institute during 1964-68, based on a commission was DACICC-200.

In the country, the first computer with parallel electronic tubes was built in 1957 at the Institute of Atomic Physics, under the supervision of engineer Victor Toma and is named CIFA-1. In 1961 at the Polytechnic Institute in Timișoara an electric tube computer has been build, MECIPT-1. Other computers built in the country of which we must mention the series FELIX C-256 etc., INDEPENDET, CORAL and some types of personal computers, then followed it. Construction of computers has been done starting 1970 at the Electronic Computer Factory in Bucharest. 


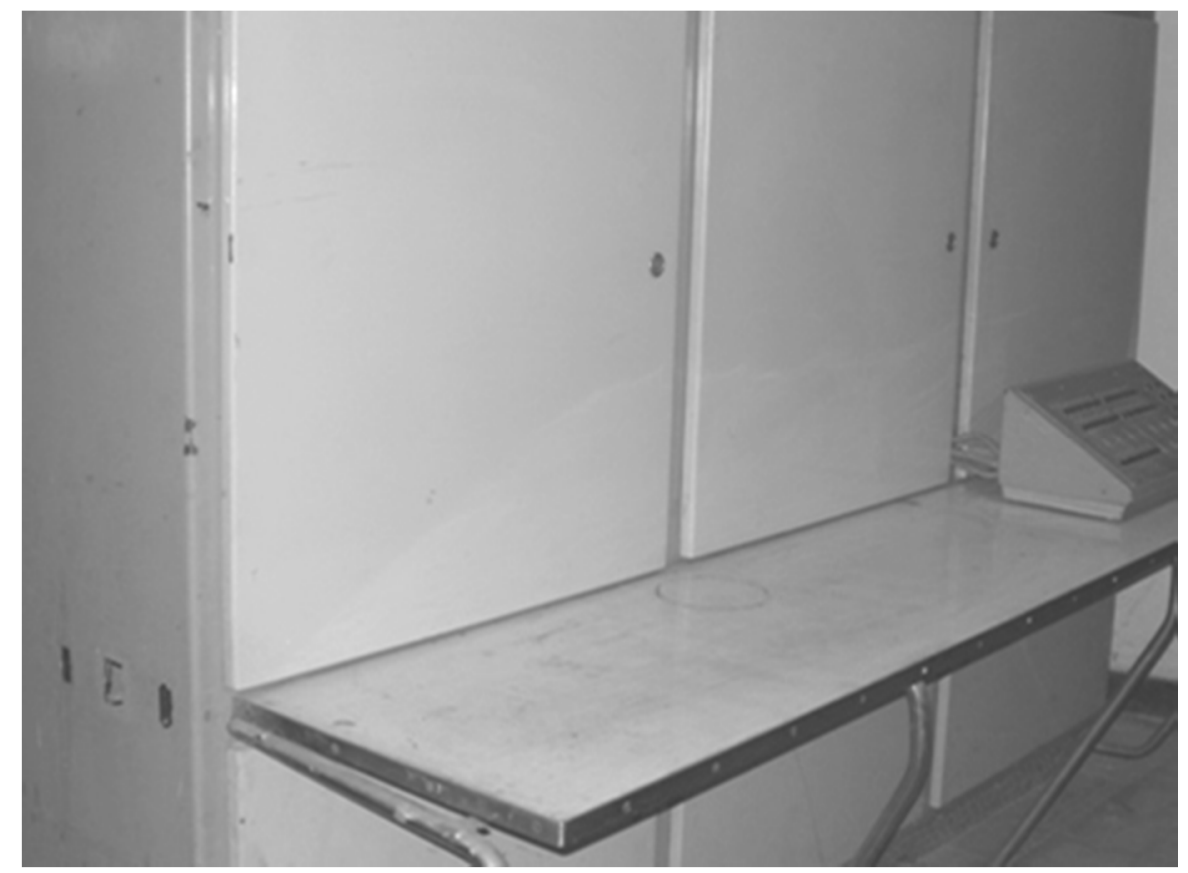

\section{Computer DACICC-1}

At the university in Cluj-Napoca, in the Faculty of Mathematics the concerns started later on but many mathematics students have participated in scientific circles organized by the Department of Mathematical Analysis, that were run by the academician Tiberiu Popoviciu and which introduced computer themes. A proper activity in the field of computers begins only when the section of calculus machine has been founded, there classes in this field were being taught. One in year IV named Calculus Machines, taught by Kiss Ernest and another one Programming in FORTRAN language taught by Professor D.D. Stancu, after his return from the United States of America in 1962.

In 1963, Professor D.D. Stancu opens the Department of Numerical and Statistical Calculus which brings together many educators with interest in this new field (D.D. Stancu, I. Maruşciac, M. Rădulescu, E. Virag, F. Oancea, Gh. Coman, Gr. Moldovan, and others). At the start of 1964, the Calculus Laboratory is also opened, under the care of the youngest of the colleagues, Gr. Moldovan. This was followed by concerns of equipping the laboratory and in trying to create something with the help of the students of the Faculty of Mathematics and those from the Faculty of Physics. The success was building a binary parallel sumator, in lab conditions, and of student level (the main contribution was that of I. Urs, student of calculus machines and V. Sgorcea, under the supervision of $\mathrm{Gr}$. Moldovan). It became clear at that time that the university is unable to engage in the building of hardware, but that its focus should stand in software and programming. Also the academician T. Popoviciu wished that research in the domain of calculus machines to be 
solely done in the institute he was running, this combined with uncertainties on the behaf of the university's rector makes the efforts of D.D. Stancu to put together a collective of specialist even more notable.

Among other specialists throughout the country, D.D. Stancu and later or Gr. Moldovan, participate at the proceedings of the GAMS group constituted from the socialist bloc states and which was centered on issues of automatic programming of computers.

During this time, we should mention some important contributions in universities on informatics. For example in 1962 at the University of Bucharest, academician Gr. C. Moisil - one of the most important disseminators of informatics and the creator of the school of theory of algebra for automatic machines - founds the very first Calculus Centre in the country which is endowed with an IBM-360 computer. In Cluj, Professor D.D. Stancu, a fine exponent of the school of numerical analysis, publishes in 1965 for the first time in Romania, in the Mathematical Gazette, A series, a group of articles on automatic programming and the ALGOL 60 language. In the same year and the same journal vol. 65(5), the first program in the FORTRAN language appears in an article by $\mathrm{Gr}$. Moldovan. Also in the same year D.D. Stancu and Gr. Moldovan publish: Romanian Terminology Project of the ALGOL-60 Language Comprising the Proper Terminology in English, French, German, and Russian, printed at the University of Cluj. I then should mention that in a paper by yours truly, published at Studia Univ. Babeş-Bolyai, MathPhysica Series in 1967, there is a first mention of an algorithm for solving a problem in the numerical analysis sector in the ALGOL-60 language. I must confess that the effective validation of this program was done in 1968 on the MINSK-22 computer while doing a specializing semester abroad at the Calculus Centre of the University of Prague. The first collection of problems referring Logical Schemes and FORTRAN Programs is published in 1973 at UBB Cluj-Napoca, and then in 1976 at the Educational and Pedagogical Publishing House in Bucharest by Gr. Moldovan. This was a real success as it was printed in large numbers (35.000 copies). Also in Cluj, the first collection of problems for COBOL language is published, authored by a collective from CTCE ClujNapoca. A mention must also be made of Theory of Algorithms, by I. Maruşciac, which develops on theoretical concepts of the Russian school.

A special place is also taken by the Calculus Technical Institute (ITC), Cluj branch under Emil Munteanu, and The Territorial Centre for Electronic Calculus (founded in 1968 and endowed with FELIX C computers in 1971) under the directorship of Vasile Petreanu. The two important exponents of informatics on the local and national stage are graduates of the Faculty of Mathematics and also come from the Calculus Institute of the Romanian Academy, Cluj-Napoca branch. 
After 1965, a collective of educators from the Technical University of Cluj-Napoca also showed an interest in computers, among them the professors: Ioan Dancea, Kalman Pusztai, Ioan Alfred Leţia, Ignat losif, Olimpiu Negru, iar după 1982, Sergiu Nedevschi, Ioan Salomie, Dorian Gorgan, Vasile Dădârlat etc.

Also at the Cluj-Napoca branch of the Institute of Atomic Physics (IFA) the interests in informatics of $\mathrm{M}$. Jalobeanu are notable especially in graphics and imagistic.

Promoting informatics through creating and implementing systems and important applications, for the most diverse fields at that time, necessitated the elaboration of a national organizational plan of informatics and calculus technique endowment. This finally takes shape in 1971, when after long and strenuous debates between economists, mathematicians, electronic engineers, and engineers from the field of automatics, the conclusion is reached that we needed to purchase a French license IRIS-50 (in its turn an American license IBM-360) for building the computers in the FELIX C 256 series etc. The contribution of academicians Manea Mănescu, Grigore C. Moisil (1906-1973), Nicolae Teodorescu (1908- 1998), Tiberiu Popoviciu (1906-1975), and Mihai Drăgănescu (1929-2010) are notable in this sense.

Parallel to this plan there was the obvious need to create another plan of preparing high school graduates and superior studies recipients with informatics knowledge. In the university environment the former name of the department of calculus machines, which was initially inspired by the Russian system and was compulsory, was replaced by a specialization in informatics, inspired by the French and which is still in use today. For this is it important to note the consistent contribution of Mihai Varia, once a employee of the Technical Publishing House, and then bought by Mihai Drăgănescu into the governmental committee tasked with endowing institutions with calculus technology. 1971 sees the foundations of informatics departments at various Faculties of Mathematics throughout the country, thus in Cluj as well, and they are meant to prepare informaticians for future calculus centers that were supposed to be organized in every county. At the polytechnic institutes the department of Automatics and Computers are opened, and at the Faculties of Economy, special departments for Economic Informatics are also created. Curricula and analytical programs specific for the field of informatics are established and the number of students is rather large.

In the summer of 1970 at the Cluj University, with the support of the rector Ştefan Pascu, in collaboration with the local ITC, the first classes for preparing educators are organized with the added help of specialists from Compagnie International pour I'Informatique - C.I.I. These were followed by classes to prepare the specialists in the calculus centers through professional reconversion of some of the graduates of the faculties 
of mathematics, physics, economical sciences, and those with electric profiles from the polytechnic universities. Cluj was one such center and this organizational task was put upon the territorial calculus centers.

In 1971, the first year of university studies for the new Department of Informatics was under two teachers who hailed from the Department of Numerical and Statistical Calculus: 1) Cornel Tarţea, who recently returned from his studies in the former U.S.S.R. on calculus machines, and 2) Grigor Moldovan, form the first series of graduates in 1963 of the department of calculus machines. In the same year the Faculty of Mathematics, Department of Department of Numerical and Statistical Calculus run by prof. Stancu, who was also pro-dean, received under placement 5 young graduates from various domains: mathematics (calculus machines) - Blaga Petru, Kasa Zoltan; electronics (computers) Lupşa Nicolae, and economics - Oprean Dumitru, Mârza lon, which are all send for specialization courses (educators) at ICI Bucharest. During the next year people have also been brought in through placement into the collective of informatics: Tâmbulea Leon (calculus machines department), Dumitrescu Dan, Landa Frederic (Physics graduates). This was a hard situation for the department as the informatics was only done on paper, without the presence of proper hardware.

A governmental decree from August 1973 marked the founding of the Central Institute for Conduct and Informatics (ICI), subordinated to the Council for SocialEconomical Organization, and which in turn had under it the territorial centers for electronic calculus and supervised informatics all around the country.

In the same year territorial centers for electronic calculus are opened in most counties, in Cluj-Napoca and Timişoara they were already functioning since 1968. In the university years $1973 / 74$ and $1974 / 75$ the students roll their programs in these centers and even for a while at the territorial center for calculus in Piteşti. The conditions for the students were very hard. Most of their difficulties were due to the use of perforated cardboard and the writing paper for the printing machine in order to create and adjust a program written in a programming language. In order to correct a simple one-character mistake in a program, they had to wait even for several days and the "serving" order was generally done on a first-come-first-served basis.

At the end of 1974, just before retirement, from what he recounts in his writings, through favorable circumstances he manages to obtain the placement of three computers for the university centers in laşi (Ioan-Cuza University), Cluj-Napoca (Babeş-Bolyai University, the P35 system), and Timişoara (Polytechnic Institute). Thus, less than one year after my return from the University of Grenoble in France, after a specialization in informatics, I was appointed as the first director of the Calculus Centre of the University 
in Cluj-Napoca, a position I filled from 1975 to 1992 (17 years). The tasks of the center, as a self-financing unity were many. We were obliged to offer our services for free to the institutions of superior education in Cluj-Napoca (Babeş-Bolyai University, Polytechnic Institute, etc.), but the self-financing also made us look for monetary sources elsewhere.

The beginnings of informatics at the Babeş-Bolyai University (UBB) in ClujNapoca could be invoked in different modes and context by the various leaders and scientific personalities of this prestigious educational institution. I believe that the most important "stone" in the foundation of this modern building that is being build through permanent reforms in UBB - using the services provided by computers - is represented by the creation in 1975 of the Calculus Centre of UBB, the only unit of its kind at the time in the important university center that is Cluj-Napoca in Romania. The inauguration of the computer FELIX-C-256 marked an important achievement for UBB, because in December 1975, the Prime-Minister of the government himself, academician Manea Mănescu was present at the event. It started with enthusiasm from the behalf of some, and skepticism from others. There were obviously many hardships, specific for beginnings, especially due to the self-financing regime. However, the important thing is that it offered the possibility of shaping a modern spirit for the students, teachers, and the rest of the University's staff, by using a computer in order to solve issues in various domains.

Self-financing from sources outside UBB, prompted a collaboration with research units and enterprises around Cluj, and these collaborations were always beneficial (the centre gained extra-budget sums in one year that were the equivalent of the one-month salaries of the entire university personnel; and all of this without counting the services it offered to the educational process, which was not highlighted in the University's accountancy). Some important collaboration connections were through the research contracts and conventions for exploitations services with the ITC, Cluj branch, its director was prof. E. Munteanu, but which did not have a FELIX-type computer for which they were creating the software. Certain collaboration also existed with the CTCE, especially for organizing one of the most important scientific manifestations in the country in the domain of informatics, namely the CONDIF Symposium.

A special collaboration was one with the prof. Marian Papahagi, a close beneficiary of the Calculus Centre of UBB in the realization of scientific research contracts. We have influenced him in taking some crucial decisions regarding the necessary endowment with PCs of the universities around the country, and especially for supporting the educational process when he was state secretary for the Ministry of National Education and responsible for the higher education. This national PC endowment plan was also accomplished. 
As the director of this center from 1975 to 1992, I have benefited from a strong collaboration and support from the deans of the Faculties of Mathematics and Informatics, as well as the rectors of UBB: Acad. Ştefan Pascu, prof.univ.dr. Ion Vlad, prof.univ.dr. Aurel Negucioiu, and Acad. Ionel Haiduc. Especially during the initial period of arranging and actually building the Centre we had the full support of the rector Ştefan Pascu.

The Calculus Centre of UBB was a representative unit in the superior education network in Romania. This institution was eventually disbanded due to the progress in calculus technology and the technology of informatics, but informatics is everywhere and in everything, mostly through specialists, which were formed at this Calculus Centre. It suffices to mention the teaching staff, which originates from the Center: prof.dr. F. Boian - PhD coordinator in informatics and department director, prof.dr. B. Pârv - PhD coordinator in informatics, cathedra director, prof.dr. I. Parpucea - collective director, conf.dr. I Chiorean, conf.dr. A. Diaconu, lector dr.ing. D. Chiorean - informatics laboratory director, lector dr. S. Damian. We should then mention their other colleagues: P. Pop, L. Munteanu, Gh. Mureşan, L. Săceleanu, L. Cobzaş, S. Petrişor, M. Topliceanu, L.F. Labo, R. Costin, ing. G. Ciplea, ec. R. Lazăr, ec. R. Pop.

Calculus technology has evolved immensely. At the time of birth of the microcomputers (PCs) and the creation of the first computer networks, which brought on the development of the Internet, the shape of the organization in calculus centers form 1975-1994 was no longer justified. Thus, there is a serious reorganization and eventual dissolution of these organizational structures. The Communications Center is founded in 1996, with a specific communication-oriented task set out, namely Internet. This new unit of informatics in the University was set up by prof.dr. F. Boian. Also a few years later, in 2002, the Center for Informatics Systems is opened. The two new informatics units on the university level are now financed from the national budget, are functioning in the frameworks of the Direction for Information and Communication Technology (DTIC), which was run at first by conf.dr. A. Andreica, and currently by prof.dr. Horia Pop.

There are many pioneering activities in informatics at UBB in which the director of the Calculus Centre - author of these lines - along with other specialists from the center were directly involved. It would be difficult to name them all. Still at least those of general interest need to be mentioned. I believe that the personal support of the Informatics Symposium and its applications in the frameworks of the Days of Cluj Academia in all its editions are a noteworthy action. The support and creation of many informatics applications of national and local interest is also quite important. Here are some of these interests. The creation of a database with the entire staff in the educational network of MEI, for which the Calculus Center of UBB was a zonal calculus center (Gr. Moldovan director), encompassing the counties of Cluj, Alba, Bistriţa, Oradea, Satu-Mare, 
Maramureş, Sălaj. This database was then exploited with our own programs in order to obtain certain statistics, evidence of didactics personnel, etc. Now these programs have been taken over by the County School Inspectorates and by the Human Resources Services of the universities, which all have their own microcomputers. There have been created programs to help with admission, programs to help with calculating the staff's salaries, and to keep the evidence of students throughout the university. All of which were in use at UBB far before any other university in the country. They were first initiated at the Calculus Center and then they were extended and re-mastered by colleagues, especially those from the Faculty of Mathematics and Informatics, which took into account the new calculus technology available in the University.

Accomplishments in informatics are numerous, but I am now confident that the most precious product of the Department of Informatics of the Faculty of Mathematics and Informatics are the few thousand graduates that are now working in important institutions and enterprises both at home and abroad. Our pride stems from them and we rejoice, I rejoice personally when I get to meet with them and they are willing to share their own important accomplishments. 